\title{
Is sclerosing encapsulating peritonitis a rare sequela of peptic ulcer disease?
}

\author{
Ian Solsky, Oscar K. Serrano, W. Scott Melvin \\ Department of Surgery, Montefiore Medical Center; Department of Surgery, Albert Einstein College of Medicine, New York, USA
}

Received: July 1, 2015

Accepted: July 26, 2015

Online Published: August 10, 2015

DOI: $10.5430 /$ css.v1n $1 \mathrm{p} 37$

URL: http://dx.doi.org/10.5430/css.v1n1p37

\begin{abstract}
Sclerosing encapsulating peritonitis (SEP) is a rare disease process in which peritoneal thickening encases the intestine and can cause bowel obstruction. While there are many proposed causes of SEP, the pathogenesis of this disease is poorly understood. Herein, we describe a case of a patient with a significant medical history that included Helicobacter pylori (H. pylori) infection, chronic peptic ulcer disease, and a resected gastrinoma who presented with a closed-loop small bowel obstruction and was found to have SEP upon exploration. Because of the absence of typical risk factors commonly associated with SEP, we propose a proinflammatory state induced by chronic peptic ulcer disease as an attributing agent in the development of SEP.
\end{abstract}

Key Words: Sclerosing encapsulating peritonitis, Peptic ulcer disease

\section{INTRODUCTION}

Sclerosing encapsulating peritonitis (SEP) is a rare disease process characterized by peritoneal thickening and fibroconnective tissue proliferation that can encase the small intestine, leading to partial or complete small bowel obstruction. ${ }^{[1-5]}$ Also referred to as the Abdominal Cocoon Syndrome, ${ }^{[2-6]}$ SEP has become increasingly recognized. ${ }^{[1,7]}$ Although congenital cases have been reported, ${ }^{[8]} \mathrm{SEP}$ is primarily classified as idiopathic or secondary SEP. Secondary SEP is most commonly associated with continuous ambulatory peritoneal dialysis; however, many other associations have been reported including recurrent episodes of infective peritonitis, treatment with beta-adrenergic blockers, ventriculoperitoneal and peritoneovenous shunts, prior abdominal surgery, tuberculosis, sarcoidosis, familial Mediterranean fever, systemic lupus erythematous, orthotopic liver transplantation, protein $\mathrm{S}$ deficiency, and fibrogenic foreign material. ${ }^{[1]}$

Herein, we describe a case of SEP in a patient with an exten- sive and long-standing history of peptic ulcer disease (PUD) that included multiple treatments for Helicobacter pylori (H. pylori) infection, gastritis, and resection of a perigastric gastrinoma. Although primary gastrointestinal neoplasms have been briefly mentioned as a potential risk factor for SEP, H. pylori infection, gastrinoma, and PUD have never been described in association with SEP.

\section{CASE REPORT}

A 55-year-old man with a complicated past medical history that included long-standing PUD, resection of a perigastric gastrinoma eleven years prior to presentation, multiple treatments for $H$. pylori seropositivity, Clostridium difficile infection, and multiple cardiovascular risk factors including pulmonary hypertension, congestive heart failure, dilative cardiomyopathy (systolic ejection fraction 35\%) and hypertension presented to the emergency department with bilious vomiting and diffuse crampy abdominal pain for the prior

*Correspondence: Ian Solsky; Email: isolsky@montefiore.org; Address: 3400 Bainbridge Avenue, MAP 4. Bronx, NY, USA. 
36 hours. He also admitted to obstipation. The patient had had a similar episode three weeks prior to presentation and was sent home from the emergency department after fluid resuscitation and symptom resolution. On examination, the patient's vital signs were within normal limits. His abdomen was massively distended and diffusely tender to palpation. A large well-healed upper midline scar was appreciated but the patient did not have any incisional or inguinal hernias. The patient also did not exhibit any manifestations of a rheumatologic process. Laboratory studies were consistent with hypochloremic metabolic contraction alkalosis and dehydration but did not suggest a systemic inflammatory state.
His WBC was $6.8 \mathrm{~K} / \mathrm{Ul}$ and his BUN and Creatinine were $28 \mathrm{mg} / \mathrm{dl}$ and $1.9 \mathrm{mg} / \mathrm{dl}$, respectively. A CT scan of the abdomen and pelvis demonstrated a conglomerate of markedly dilated small bowel loops in the left lower quadrant, concerning for an internal hernia, with marked distortion of the small bowel mesentery in a whirl, suggestive of a small bowel volvulus (see Figure 1A). Furthermore, upon closer review, an ill-defined membrane appeared to encase the volvulized segment of small bowel (see Figure 1B). A nasogastric tube was inserted with evacuation of $600 \mathrm{cc}$ of gastric contents. The patient was taken to the operating room for emergent surgery.

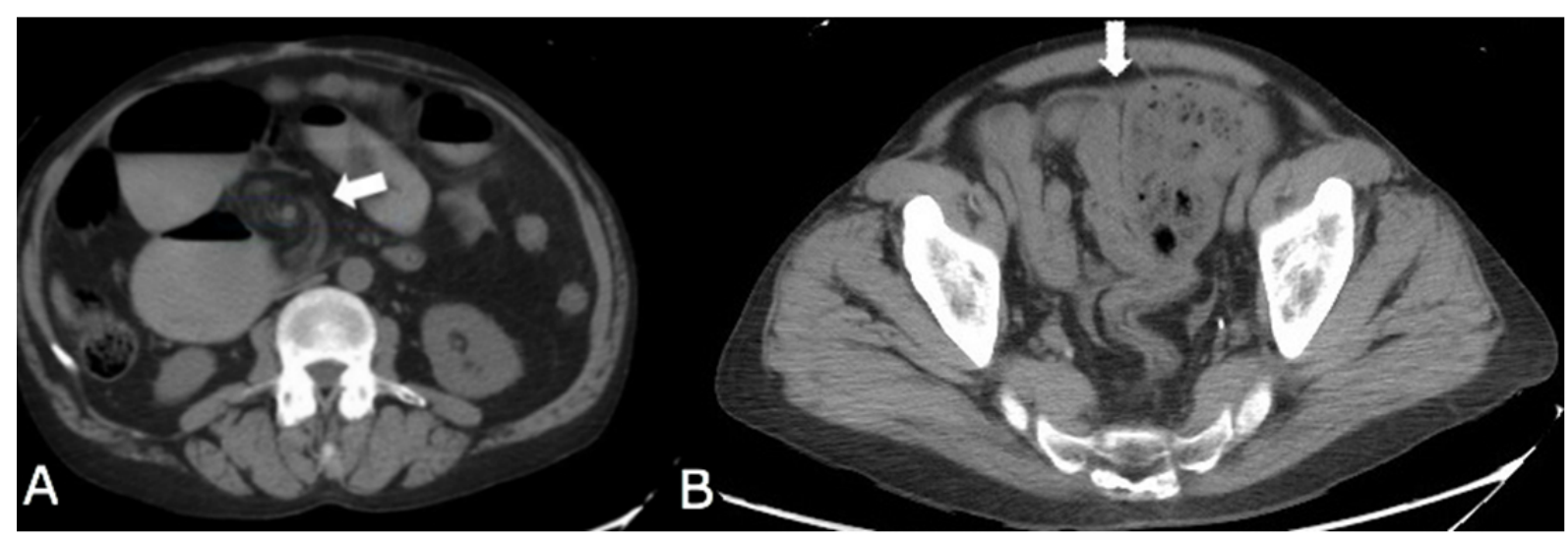

Figure 1. Abdominal computed tomography images showing a whirl pattern (arrow), a classic sign of closed loop small bowel obstruction or volvulus (A), and a fibrotic band (arrow) encasing and anterior to a loop of bowel (B)
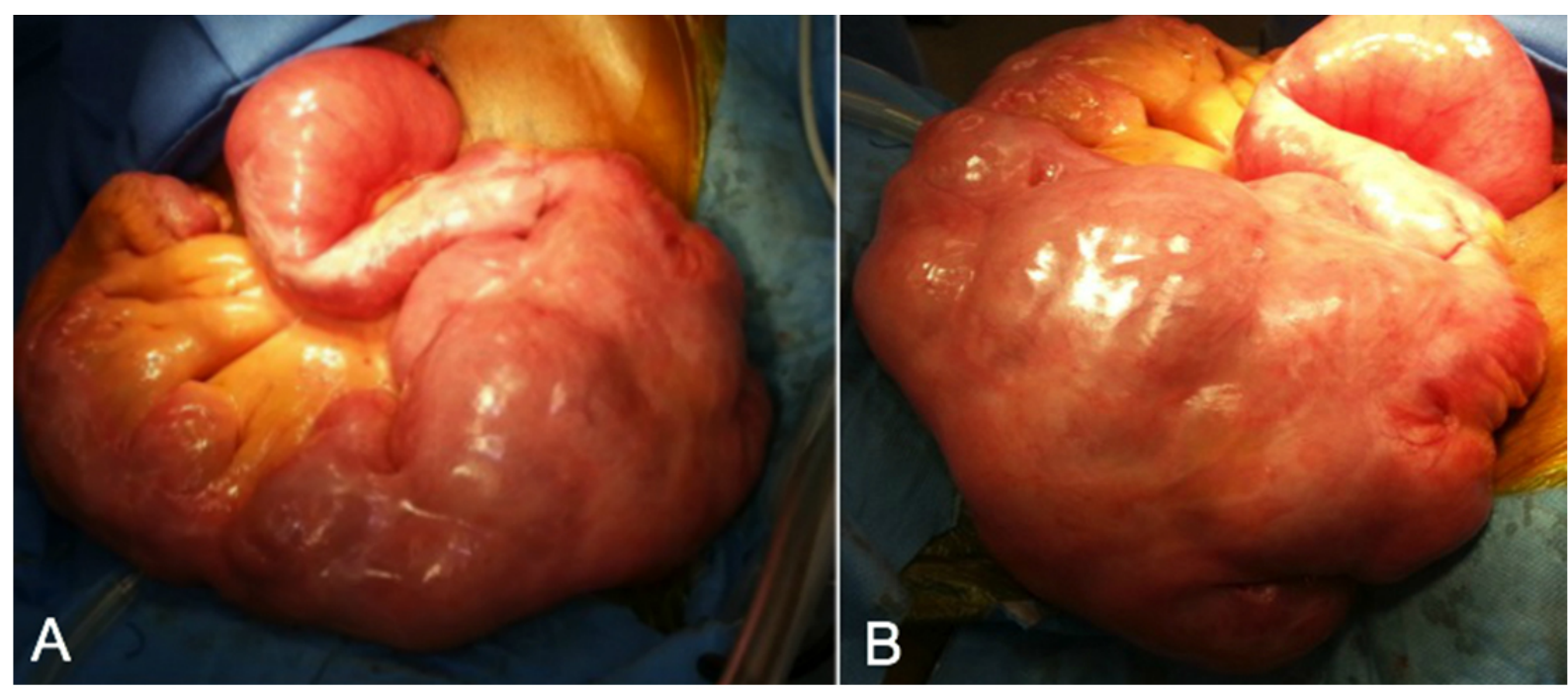

Figure 2. Intraoperative images demonstrating thick fibroconnective tissue encasing a segment of small bowel (A, B)

Upon exploration, the entire small bowel appeared to be covered by very thick fibroconnective tissue (see Figure 2) divided among 3 separate clusters. The largest cluster, which coincided with the volvulized segment of bowel, was located approximately $20 \mathrm{~cm}$ from the ligament of Treitz. Addition- ally, purulent fluid was drained from the pelvis which eventually grew rare Klebsiella pneumoniae, confirming a bacterial peritonitis. Extensive lysis of adhesions was performed with the decortication of the small bowel rind, which on pathologic evaluation demonstrated portions of mesothelial-lined 
fibroconnective tissue with areas of sclerosis and chronic inflammation. There were no complications during the procedure.

Post-operatively, the patient recovered well. By postoperative day 3 , he was started on a regular diet and was discharged home on postoperative day 5 .

\section{Discussion}

Even though SEP is a rare cause of small bowel obstruction (SBO), the majority of reported cases of SEP present with symptoms of SBO. ${ }^{[2-6]}$ Common CT findings of SEP include peritoneal thickening, loculated fluid collections, peritoneal calcifications, tethering or matting of small bowel, marked enhancement of the peritoneum, and thickening of the bowel wall. ${ }^{[9]}$ To our knowledge, SEP has never been reported to present with a volvulized closed loop obstruction, manifested by a whirl sign.

While there are many proposed secondary causes of SEP, the pathogenesis of this intra-abdominal phenomenon is poorly understood. The most likely pathophysiologic explanation is a subclinical peritonitis leading to sclerosis and the subsequent formation of a cocoon-like membrane, which can cause bowel obstruction. ${ }^{[2-6]}$

Although the etiology of a heightened inflammatory state in our patient is likely multifactorial, including his prior history of gastrinoma, special consideration should be given to his recurrent $H$. pylori infections with recalcitrant PUD. The presence of bacterial peritonitis in the absence of liver cirrhosis or a surgically-rectifiable infection, could be related to his PUD treatment since the use of proton pump inhibitors (PPI) has been implicated with increased bacterial overgrowth and translocation due to hypochlorhydria. ${ }^{[10]}$ Furthermore, studies have demonstrated that PPIs can significantly increase the risk of spontaneous bacterial peritonitis in patients with cirrhosis. ${ }^{[11]}$

Additionally, H. pylori infection is known to cause a cytokinemediated inflammatory response that progresses through a series of precancerous stages including gastritis, intestinal metaplasia and dysplasia, with approximately $10 \%$ of infected individuals developing peptic ulcer disease and $1 \%$ $3 \%$ progressing to gastric malignancies. ${ }^{[12,13]}$ We speculate that this same process could potentially contribute to SEP development. Epidemiologic studies have shown that there is a correlation between $\mathrm{H}$. pylori infection and extragastric disease, especially those characterized by persistent, low grade systemic inflammation. ${ }^{[14]}$ With evidence that systemic immunomodulatory and proinflammatory effects can be caused by $H$. pylori colonization with chronic $\mathrm{PUD}^{[15]}$ as well as excess gastrin release, ${ }^{[16]}$ these disease processes, in theory, could culminate in a field-defect manifested as subclinical peritonitis with the eventual development of SEP.

We present a patient with a complicated medical history of H. pylori infection, PUD, and gastrinoma who developed a closed-loop obstruction requiring surgical exploration as a result of SEP. His substantial PUD risk factors and the absence of any other definitive etiologic agent for SEP, lead us to suspect a contributive role. We hypothesize that $H$. pylori seropositivity and PUD may have contributed to an inflammatory response that led to the progression of SEP. Albeit entirely inferential, his significant ulcerogenic risk factors warrant further study as a potential source of intra-abdominal inflammation leading to SEP.

\section{CONFLICTS OF INTEREST Disclosure}

The authors of this manuscript have no conflicts of interest to disclose.

\section{REFERENCES}

[1] Serter A, Kocakoc E, Cipe G. Supposed to be rare cause of Intestinal Obstruction; abdominal cocoon: report of two cases. Clin Imaging. 2013; 37(3): 586-9. PMid: 23041158. http://dx.doi.org/10. 1016/j.clinimag. 2012.08.010

[2] Foo K, Ng K, Rauff A, et al. Unusual small intestinal obstruction in adolescent girls: the abdominal cocoon. Br J Surg. 1978; 65(6): 427-40. PMid: 656764. http://dx.doi.org/10.1002/bjs.180 0650617

[3] Deeb L, Mourad F, El-Zein Y. Abdominal cocoon in a man: preoperative diagnosis and literature review. J Clin Gastroenterol. 1998; 26(2): 148-50. PMid: 9563929. http://dx.doi.org/10.1097/0 0004836-199803000-00013

[4] Sieck J, Cowgill R, Larkworthy W. Peritoneal encapsulation and abdominal coccon. Case report and a review of the literature. Gas- troenterology. 1983; 84(6): 1597-1601. PMid: 6840491.

[5] Cambria R, Shamberger R. Small bowel obstruction caused by the abdominal cocoon syndrome: possible association with the LeVeen shunt. Surgery. 1984; 95(4): 501-3. PMid: 6710346.

[6] Wei B, Wei H, Guo W, et al. Diagnosis and treatment of abdominal cocoon: a report of 24 cases. Am J Surg. 2009; 198(3): 348-53. PMid: 19217609. http://dx.doi.org/10.1016/j.amjsurg. 2 008.07 .054

[7] Akbulut S. Accurate definition and management of idiopathic sclerosing encapsulating peritonitis. World J Gastroenterol. 2015; 21(2): 675-87. PMid: 25593498. http://dx.doi.org/10.3748/wjg.v 21.i2. 675

[8] Sahoo SP, Gangopadhyay A, Gupta D, et al. Abdominal cocoon in children: a report of four cases. J Pediatr Surg. 1996; 31(7): 987-8. http://dx.doi.org/10.1016/S0022-3468(96) 90431-5 
[9] George C, Al-Zwae K, Nair S, et al. Computed tomography appearances of sclerosing encapsulating peritonitis. Clin Radiol. 2007 62(8): 732-7. PMid: 17604760. http://dx.doi.org/10.1016/j .crad.2007.01.022

[10] Bavishi C, Dupont HL. Systematic review: the use of proton pump inhibitors and increased susceptibility to enteric infection. Aliment Pharmacol Ther. 2011; 34(11-12): 1269-81. PMid: 21999643. http://dx.doi.org/10.1111/j.1365-2036.2011.04874.x

[11] Min Y, Lim K, Min B, et al. Proton pump inhibitor use significantly increases the risk of spontaneous bacterial peritonitis in 1965 patients with cirrhosis and ascites: a propensity score matched cohort study. Aliment Pharmacol Ther. 2014; 40(6): 695-704. PMid: 25078671. http://dx.doi.org/10.1111/apt.12875

[12] De Falco M, Lucariello A, Iaguinto S, et al. Molecular mechanisms of Helicobacter pylori pathogenesis. J Cell Physio. 2015; 230(8): 1702 7. PMid: 25639461. http://dx.doi.org/10.1002/jcp. 24933
[13] Grin A, Kim Y, Mustard R, et al. Duodenal gastrinoma with multiple gastric neuroendocrine tumors secondary to chronic Helicobacter pylori gastritis. Am J Surg Pathol. 2012; 36(6): 935-940. PMid: 22588069. http://dx.doi.org/10.1097/PAS.0b013e3 1824 babc2

[14] Franceschi F, Zuccala G, Roccarina D, et al. Clinical effects of Helicobater pylori outside the stomach. Nat Rev Gastroenterol Hepatol. 2014; 11(4): 234-42. PMid: 24345888. http://dx.doi.org/10. 1038/nrgastro.2013.243

[15] Cadamuro A, Rossi A, Maniezzo N. Helicobacter pylori infection: host immune response, implication on gene expression and microRNAs. World J Gastroenterol. 2014; 20(6): 1424-37. PMid: 24587619. http://dx.doi.org/10.3748/wjg.v20.i6.1424

[16] Calatayud S, Alvarez A, Victor V. Gastrin: an acid-releating proliferative and immunomodulatory peptide. Mini Rev Med Chem. 2010; 10(1): 8-19. PMid: 20380639. http://dx.doi.org/10.2174/1 38955710791112532 